\title{
Influence of Location on the Relationship between Mass Media and Risky Sexual Behaviour among Adolescents in Edo North Senatorial District
}

\author{
Ugoji F. N. ${ }^{1 *}$ Ena-Israel E. G. ${ }^{2}$ \\ 1. Department of Guidance and Counselling, Delta State University, P.M.B.1, Abraka, Delta State, Nigeria \\ 2. Department of Guidance and Counselling, Delta State University, P.M.B.1, Abraka, Delta State, Nigeria \\ Email of the Corresponding author: ngougoji@yahoo.com
}

\begin{abstract}
This study investigated the influence of location on the relationship between mass media and risky sexual behaviour among adolescents. The study was guided by two research questions and two null hypotheses. The research design adopted in the study was a correlation research design. A total of 500 SS 2 students were sampled from a population of 17,608 students in the eight Local Government Areas of Edo North Senatorial District through a multistage sampling procedure. Questionnaire was the instrument used for data collection, which was validated through experts' judgement and factor analysis. The reliability of the instrument was estimated with Cronbach alpha reliability coefficient. The coefficient obtained include 0.89, and 0.96 for Mass Media Rating Scale and Risky Sexual Behaviour Rating Scale respectively. The data obtained were analysed with regression statistics at 0.05 level of significance. The findings of this study revealed that there is a significant relationship between mass media and risky sexual behaviour among adolescents. However, the study established that there is no significant influence of school location on the relationship between mass media and risky sexual behaviour. Based on these findings, it was recommended amongst others that parents should be mindful of the kind of content students are exposed to in the mass and social media platforms.
\end{abstract}

Keywords: Mass Media; School Location; Risky Sexaul Behaviour; Adoelscents.

DOI: $10.7176 / \mathrm{JEP} / 11-21-22$

Publication date:July 31 st 2020

\section{Introduction}

The period of adolescence occupies a unique stage in every individual's life. It is a period of transition from childhood to adulthood. It is a time where a lot of physiological as well as anatomical changes take place resulting in reproductive maturity in the individual. Hence, the stage is often referred to as a period of storm and stress. Many adolescents manage this period successfully while others experience major stress and find themselves engaging in behaviours that place their well-being at risk. One of such behaviours is risky sexual behaviour. Secondary school students in Edo North Senatorial District who are in this stage of development, not only exhibit risky sexual behaviours, observations as well as empirical studies have shown that these behaviours are mostly risky and not in the overall interest of the individual.

Risky sexual behaviours are defined as sexual activities that may expose a person to the risk of sexually transmitted infections (STIs), including HIV and unplanned pregnancies. This involves the number and types of partnerships, sexual acts and sexual orientation. Some of these behaviours include unprotected sex, multiple sexual partners, forced sex and sex for money. Other elements include early sexual intercourse and untreated sexually transmitted diseases. Ugoji (2014) identified homosexuality, lesbianism and sexual orgies among some of the forms of risky sexual behaviour. Observations and empirical studies have shown that adolescents often engage in risky sexual behaviour. For example, Famutimi and Oyetunde (2014) found that the average age at menarche is declining worldwide; there is a decline in the age of first sexual onset, an increasing number of sexually active adolescents, and high-risk sexual behaviours among adolescents. Recent studies have shown that adolescents become sexually active at an older age than in previous years. For example, young people face a longer period of sexual maturity and pre-marital sexual activities (World Health Organization, WHO, 2006). Adeleye, Oluwatosin, Adefisoye, Oluwaseyi, and Abiola (2014) also found that many young people engage in risky sexual activities, including early initiation into sexual activity, sex with many partners, low and inconsistent use of condom. There seems to be some connection between location and risky sexual behaviour among adolescents. This is because the environment a child grows up in has a way of influencing the child. For instance adolescents in rural areas are seen to be more conservative than their counterparts in urban areas who have been exposed to various lifestyles capable of corrupting the mind. The study of Folayan, Adebajo, Adeyemi and Ogungbemi (2015) confirms the fact that there is difference in sexual behaviour and practices of adolescents residing in urban and rural areas and that the negative tendency seems to be predominantly high in urban cities. Risky sexual behaviour among teenagers is a big concern 
and these behaviours can lead to unwanted pregnancies, teenage parenthood, illegitimate children, feelings of shame and emotional instability. In some cases, abortion is attempted or committed, sometimes leading to premature death of the mother and child. These behaviours are common among adolescents in Edo North Senatorial District.

A growing proportion of these students not only initiate sex at an early age, but also have multiple sexual partners for lack of information and education, resulting in a high number of illegal abortions. A significant number of these students are sent or are shamelessly and voluntarily removed from school due to pregnancy during adolescence. Many female students may have unprotected sex with health consequences due to lack of knowledge and information. Various reasons have been cited for this social illness: peer pressure, financial gain, lack of cohabitation with both parents, poor family history, family income, family types, lack of knowledge about reproductive health, family dysfunction, poor parental communication, and parenting styles. However, the researchers are interested in the influence of location on the relationship between mass media and adolescent risky sexual behaviour. This study is aimed at examining the influence of location on the relationship between mass media and adolescent risky sexual behaviour in Edo North Senatorial District.

\section{Literature Review}

The term adolescence is derived from the Latin word adolescence which means "growing up". While adolescent refer to an individual who is between the range of 12-19 years. It is also regarded as the physical and mental human development that occurs between childhood and adulthood. The transition involves biological (i.e. puberty), social and psychological changes. Adolescence can be seen as a stage in the life span through which individual passes before adulthood. It is also a period of great emotional stress. Whatever happens during this developmental stage goes a long way in affecting the individual either positively or negatively. These changes are associated with involvement with one's peers. As children grow, develop and move into early adolescence, involvement with peer and attraction of peer identification increases. As a result of the social acknowledgement that adolescents look for, they are under a certain amount of pressure that drives them to abide by the peers ${ }^{\text {ee }}$ convictions or rejections.

Ngwoke and Eze (as cited in Ekwueme, 2012) perceived adolescence as the onset of puberty, the period of physical growth and development that brings to an end childhood and enables the growing person to achieve adult size, shape and sexual reproductive capacity. Adolescence is also a time when risks of sexual and other forms of abuse, exploitation and violence are high, and when the drive for autonomy and self-definition often means a reduced reliance on parents and other adults as trusted sources of guidance and support (Aggleton, Hurry \& Warwick, 2000). Adolescence is the biological changes from childhood into mature adulthood capable of reproduction (Aggleton et al 2000).

Risky sexual behaviours can be defined in a number of ways. It includes early sexual debut, unprotected sexual activity, inconsistent use of condoms, high risk partners (injection drug users), survival sex (sex in exchange for money, drugs, food or shelter) or sex with a partner who has other partners or more than one partner at a time (Baumeister, Flores \& Marin, 1995). Risky sexual behaviour can take several forms ranging from a large number of sexual partners, or engaging in risky sexual activities to sexual intercourse under the influence of substances such as alcohol or cocaine (Robinson, 1999).

Risky sexual behaviour is also defined as any behaviour that increases the probability of negative consequences associated with sexual contact, including HIV and AIDS or other sexually transmitted diseases (STDs) and unplanned pregnancy (De Vincenzi, 1994). These behaviours are considered in two broad categories namely: indiscriminate behaviours such as having multiple partners; having risky, casual or unknown partners; failure to discuss risk topics prior to intercourse; and failure to take protective actions such as use of condoms and birth control.

Mass media is defined as those media that are designed to be consumed by large audiences through the agencies of technology (Wakefield, et al., 2010). An array of communication media reaches large numbers of the public, including radio, television, movies, newspapers, and magazines. The Internet is a worldwide, publicly accessible network of interconnected computer networks that transmits information and services such as electronic mail, online chat, title transfer, interlinked web pages, and other documents of the World Wide Web (Brown, 2010).

Oladeji \& Ayangunna (2017) argues that young people experience a vast amount of changes in their physical, emotional and social maturity. During this stage, outside influences are particularly capable of affecting teenagers' thoughts and behaviours and one of such influence is the social media. Adolescents consistently site the mass media as important sources of sexual information (Brown, L’Engle, Pardun, Guo, Kenneavy, Jackson, 2006). 
Television which was considered the most dominant medium has now been coupled with various other new media and adolescents are spending good amount of time using media. Jones \& Fox (2009) mentioned that 93\% of children in the age group of 12- 17 years are found to be searching different sites on internet, $71 \%$ have a mobile phone, $57 \%$ watch 2 videos on computer, $65 \%$ visit social networking sites, $38 \%$ make on-line purchases and $28 \%$ get health information.

Collins, Elliot, Berry, Kanouse, et. al. (2004) opines that sexual behaviour is strongly influenced by culture and the television is an integral part of the adolescent culture as the average adolescent spends at least three hours daily on the television. The television has been commonly cited by parents and policy makers as promoting sex among adolescents which is a common place where sexual messages are displayed. Gerbner, Gross, Morgan \& Signorielli (1986) posits that this high exposure of sexual contents in television may affect adolescents developing beliefs about cultural norms as the illusion that sex is more central to daily life than it truly is may be creating, thereby promoting early sexual initiation.

Oladeji \& Ayangunna (2017) asserts that the influence of media depends largely on the content it contains, and the television viewing, remains the most common medium and platform, making up the largest chunk of adolescents' media use. Television includes a great deal of sexual content, having an average of five scenes with sex in each hour of programming. The amount of sexual content that youth encounter varies across these platforms. Television, music, movies, favourite internet sites, and magazines used by adolescents contain sexual content. However, the content is concentrated much more strongly in music. ( 40 percent contained sexual content) than in movies (12 percent) or television (11 percent), and only 6 percent of the internet sites they examined contained sexual content. Ward (1995) reports that adolescents who watch television shows with high sexual content, such as night-time soap operas and music videos, tend to have more liberal sexual attitudes and believe that their peers are more sexually active, as opposed to those who do not watch such shows.

An exposure to social models provided on television may also alter beliefs about the likely outcome of engaging in sexual activities. Collins, Elliot, Berry and Kanouse (2004) opines that adolescents who see characters having casual sex without experiencing negative consequences will be more likely to adopt the behaviours portrayed because according to the social learning theory, new behaviours can be acquired by observing and imitating others. Klein et al (1993) opines that media models may also play a role in the development of healthy behaviours by providing behavioural scripts or schemas for health-related activities. Collins, Elliot, Berry, Kanouse et al (2004) also agrees that televised sexual portrayals can theoretically inhibit sexual activities when they include depictions of sexual risks - such as the possibility of contracting an STD or becoming pregnant, abstinence, or the need for sexual safety. But such type of portrayal occurs in only $15 \%$ of shows with sexual content, that is, 1 out of 7 television shows that include sexual content includes any safe sex messages and nearly two-third of these instances are minor or inconsequential, hence sexual content on television is far more likely to promote sexual activity about adolescents than discourage it, as television programming contains high levels of sexual content, includes little information about sexual risks, and is an important source of information about sex for adolescents (Ashby, Arcari \& Edmonson, 2006).

Olumuyiwa and Oladipupo-Okorie (2014) investigated the influence of some perceived factors (Mass Media and peer influence) on pre-marital sex among 500 randomly selected secondary school students in Ojo Local Government Area of Lagos state, southwest Nigeria. The instrument used to collect data was a modified 4- point Likert scale questionnaire designed by the researchers and validated by experts in test and measurement in Lagos State University, Lagos State, Nigeria. A test-retest method with a correlation co-efficient of 0.76 was used to determine the reliability of the instrument when it was subjected to Pearson's Product Moment Correlation Coefficient, an indication of the reliability and suitability of the instrument for the study. Data collected were analysed with frequency count and simple percentage while chi-square (X2) was used to test the hypotheses at 0.05 level of significance. The results showed that mass media and peer group were perceived factors influencing pre-marital sex among secondary school students in Ojo Local Government Area of Lagos State. This study is related to the present study because, they both deal with adolescents. However, this study is on premarital sex while the present study is on risky sexual behaviour.

Kimani (2014) examined the relationship between levels of exposure to mass media and students' deviant behaviours in selected secondary schools within Nakuru County Kenya. The study employed survey research design. In view of this, questionnaires were used to collect both qualitative and quantitative data. The independent variable in the study was levels of exposure to mass media. The dependent variables were students' Drug abuse, aggression, Sexual violence and physical violence. The study was carried out in the 3 Sub-counties of Nakuru town, Molo and Nakuru North, within Nakuru County, Kenya. The sample size for this study was 482 sampled 
from a total student population of 12,300 from the 3 selected Sub-counties. The study areas were purposively sampled while stratified random sampling and simple random sampling were used to sample schools and students respectively. The study used 8 public secondary schools distributed as follows, 3 were Sub-county day and mixed, 1 provincial day and mixed, 2 provincial boarding and mixed, 1 national boys boarding and 1 national girls boarding. All form one, two and three students in the specified categories formed the accessible population of 482 students. The study used questionnaire to collect data. The instruments were pre-tested in 3 schools, randomly selected from the 3 Sub-counties. Each school had 20 students selected randomly. Quantitative data was analysed using Statistical Package for Social Sciences (SPSS) version 20 for Windows. Specifically, Chi square and Pearson correlation statistics were used to test the significance of the stated null hypotheses, set at $\alpha=0.05$. Qualitative data applied thematic analysis while descriptive statistics such as percentages, frequencies and means were used to summarize data.

The key findings indicated that levels of exposure to mass media influences students to drug abuse $(\mathrm{P}=0.007$ that is $<0.05$ ). Test done proved that levels of exposure to mass media are related to students' Drug abuse, aggression, sexual violence and physical violence. The statistical test results showed that time spent watching TV or video has an influence on students' physical violence levels $(\mathrm{P}=0.029$ which is $<0.05)$. Moreover, the statistical test results showed that time spent watching TV or video has an influence on students' levels of risky sexual behaviour $(\mathrm{P}=0.004$ which is $<0.05$ ). This study is related to the present study because, they both deal with influence of mass media on the behaviour of secondary school students. However, this study is on deviant behaviour while the present study is on risky sexual behaviour.

There seems to be some connection between location and risky sexual behaviour among adolescents. The study by Folayan, Adebajo, Adeyemi and Ogungbemi (2015) confirms the fact that there is difference in the sexual behaviour and practices of adolescents and young persons residing in the urban and rural areas. This negative tendency seems to be predominantly high in urban cities because research supports the view that adolescents in the rural areas are more conservative in the issue of risky sexual activities. This is because, parents are able to monitor and prevent this activity among their children.

A study conducted by Slap, Lot, Huang, Daniyam, Zink and Succop (2003) showed that risky sexual behaviour is higher in urban than in rural areas. This is because adolescents in rural areas are surrounded by various norms and traditions, which they must uphold or face the corresponding consequences. According to Ajuwon, Olaleye, Famoroju and Ladipo (2006), students whose schools were located in urban areas were 3 times more likely to have had sexual intercourse than those in the rural schools while those in semi-urban schools were almost 2 times more likely to have had sex than students in rural areas. A study by Karl and Supa (2005) on HIV/AIDS knowledge and sexual behaviour among junior secondary school students in South Africa reported a lower sexual behaviour among urban students than rural students.

Azmawati, Hazariah, Shamsul, Norfazilah, Azimatun and Rozita (2015) investigated Risk taking behaviour among urban and rural adolescents in two selected districts in Malaysia. The study adopted a comparative cross-sectional study. A total of 306 adolescents were selected through multistage sampling from two selected schools with involvement of their parents. The instrument of data collection used was a questionnaire and the data were analysed using multiple logistic regress statistics. The prevalence of risk-taking behaviours was $81.7 \%$ in the urban and $83.7 \%$ in the rural area $(\mathrm{p}=0.650)$. Parental background factors such as parent's education level, marital status, health status, and peer group influence were unrelated with risk taking behaviour among adolescents. The multiple logistic regression test showed that being a male $(\mathrm{AOR}=4.55,95 \% \mathrm{CI}=2.28-9.07)$, inadequate number of bedrooms $(\mathrm{AOR}=11.54,95 \% \mathrm{CI}=1.48-89.75)$, and presence of family conflict $(\mathrm{AOR}=3.64,95 \% \mathrm{CI}=1.49$ 8.89 ) were the predictors among adolescents for risk taking behaviour in rural areas.

Based on the theoretical and empirical literature reviewed, it has been observed that many studies have been conducted to show how mass media and location influence adolescent behaviour, including risky sexual behaviour. However, there is still much to study. Indeed, none of the studies reviewed examined the joint influence of mass media and location on risky sexual behaviour in adolescents. In addition, to the knowledge of the researcher, no studies have been conducted on the influence of location on the relationship between mass media and risky sexual behaviours in Edo North Senatorial District. These have created a serious gap in literature that this study filled.

\section{Research Questions}

The following research questions guided the study: 
1. What is the relationship between mass media and risky sexual behaviour among adolescents in Edo North Senatorial District?

2. What is the influence of school location on the relationship between mass media and risky sexual behaviour among adolescents in Edo North Senatorial District?

\section{Hypotheses}

The following null hypotheses formulated were tested at 0.05 level of significance:

1. There is no significant relationship between mass media and risky sexual behaviour among adolescents in

Edo North Senatorial District

2. There is no significant influence of school location on the relationship between mass media and risky sexual behaviour among adolescents in Edo North Senatorial District

\section{Methods \\ Research Design}

This study adopted a correlation research design. The choice of correlation design is because it helped to examine the relationship that existed between mass media, location and risky sexual behaviour among adolescents in secondary schools.

\section{Population and Sample}

The population of the study comprised all public senior secondary school 2 (SSS 2) students in Edo North Senatorial District. There are 179 public secondary schools and a total of 19,555 SS 2 students in the eight local government areas of Edo North Senatorial District. The study sample included 500 students from the Edo North Senatorial District. Students were selected from Edo North Senatorial District schools using a multi-stage sampling procedure; the first phase of sampling selected four local government areas from the eight Local Government Areas of the Edo North Senatorial District. This was done by a simple random sampling technique.

The second stage selected 20 schools from the four selected local government areas (five schools from each Local Government Area). This was done using a simple random sampling technique, with the procedure described above. The third phase of sampling selected a total of 25 students from each school, for a total of 500 students. This was done using a purposive sampling technique. That is, the students in the schools were grouped into boys and girls. A total of 13 female and 12 male students were selected from each school.

\section{Research Instruments}

A questionnaire was used for data collection in this study. The questionnaire is titled Questionnaire on Mass Media, Location and Adolescent Risky Sexual Behaviour (QMMLARSB). It contains 2 sections. Section A contains respondent demographics such as sex, location and age; while Section B contains the the Mass Media Rating Scale (MMRS), and Risky Sexual Behaviour Rating Scale (RSBRS). The MMRS contains 12 items that measured how much students are influenced by the mass media. They were structured on a 4-point scale, ranging from 1 for strongly disagree to 4 for strongly agree. The RSBRS contains 22 items that measured the degree of sexual risky behaviour of students. They were structured on a 4-point scale, ranging from 1 for strongly disagree to 4 for strongly agree.

\section{Validity and Reliability}

The face validity of the instruments was established by three experts in guidance and counselling who assessed the instruments for appropriateness and suitability to the objective of the study, and their suggestions were effected. In order to establish the reliability of the instruments, the data generated were analysed with Cronbach Alpha Reliability Coefficient to determine the internal consistency and the coefficient obtained was 0.89 , and 0.96 for MMRS and RSBRS respectively. 


\section{Procedure}

The questionnaire was administered directly to the respondents by the authors with the help of 3 research assistants. The questionnaire was retrieved immediately at the end of the exercise and a total of 447 out of 500 copies administered were retrieved in good condition. This indicates a percentage retrieval rate of $89 \%$.

\section{Data Analysis}

The data obtained were analysed using linear and multiple regression statistics at a significance level of .05 . The analysis was carried out with the use of Statistical Package for Social Sciences (SPSS) version 23.

\section{Results}

Research Question 1: What is the relationship between mass media and risky sexual behaviour among adolescents in Edo North Senatorial District?

Hypothesis 1: There is no significant relationship between mass media and risky sexual behaviour among adolescents in Edo North Senatorial District

Table 1: Regression analysis of the relationship between mass media and risky sexual behaviour among adolescents in Edo North Senatorial District

\begin{tabular}{|c|c|c|c|c|c|}
\hline Model & Sum of Square & df & Mean Square & $\mathbf{F}$ & Sig \\
\hline Regression & 10035.886 & 1 & 10035.886 & \multirow{3}{*}{150.500} & \multirow{3}{*}{$.000^{\mathrm{b}}$} \\
\hline Residual & 29674.172 & 445 & 66.684 & & \\
\hline Total & 39710.058 & 446 & & & \\
\hline \multicolumn{6}{|c|}{ Variables in Equation } \\
\hline \multirow[t]{2}{*}{ Model } & \multicolumn{2}{|c|}{ Unstandardized Coefficient } & $\begin{array}{l}\text { Standardised } \\
\text { Coefficient }\end{array}$ & $\mathbf{t}$ & Sig \\
\hline & B & Std. Error & Beta & & \\
\hline Constant & 8.313 & 1.328 & & 6.262 & .000 \\
\hline Mass Media & 672 & .055 & .503 & 12.268 & .000 \\
\hline
\end{tabular}

$\alpha=0.05, \mathrm{R}=0.503, \mathrm{R}$-Square $=0.253$

a. Dependent Variable: Risky Sexual Behaviour

b. Predictors (Constant): Mass media

Table 1 is the result of a regression analysis conducted to determine the relationship between mass media and Risky sexual behaviour among adolescents in Edo North Senatorial District. From the result, F(1, 446) $=150.500$, $\mathrm{p}<0.05$ level of significance. Based on this result, the null hypothesis is therefore rejected, an indication that there is a significant relationship between mass media and risky sexual behaviour among adolescents in Edo North Senatorial District. As indicated in the beta value of 0.50 , mass media accounted for $25 \%$ of the variance in risky sexual behaviour among adolescents in Edo North Senatorial District.

Research Question 2: What is the influence of school location on the relationship between mass media and risky sexual behaviour among adolescents in Edo North Senatorial District?

Hypothesis 2: There is no significant influence of school location on the relationship between mass media and risky sexual behaviour among adolescents in Edo North Senatorial District

Table 2: Pearson's correlation of the influence of school location on the relationship between mass media and risky sexual behaviour among adolescents in Edo North Senatorial District

\begin{tabular}{|c|c|c|c|c|c|c|c|}
\hline School Location & Variable & n & $\mathbf{r}$ & $Z_{\text {obs }}$ & & & Decision \\
\hline & Mass Media & & & & \multirow[t]{3}{*}{1.31} & \multirow[t]{3}{*}{1.96} & \multirow{3}{*}{$\begin{array}{l}\text { Not } \\
\text { significant }\end{array}$} \\
\hline Urban & $\begin{array}{l}\text { Risky Sexual Behaviour } \\
\text { Mass Media }\end{array}$ & 231 & 0.428 & & & & \\
\hline Rural & Risky Sexual Behaviour & 216 & 0.546 & & & & \\
\hline
\end{tabular}

Table 2 shows a Pearson's correlation analysis of the relationship between mass media and risky sexual behaviour among adolescents in Edo North Senatorial district. The result shows that for urban, $\mathrm{r}=0.428$ while for rural, $\mathrm{r}=0.546$. In order to determine the finluence of school location on the relationship between mass media and risky sexual behaviour among adolescents in Edo North Senatorial District, the statistical signficiance of the difference between the correlation coefficient of urban and rural students was conducted. The result showed that $Z_{\mathrm{obs}}=1.31$, is less than $1.96 \mathrm{Z}$-critical value. Hence, the null hypothesis is accepted, which means that there is no significant 
influence of school location on the relationship between mass media and risky sexual behaviour among adolescents in Edo North Senatorial District.

\section{Discussion}

The finding revealed that there is a significant relationship between mass media and risky sexual behaviour among adolescents. This means that mass media has an impact on risky sexual behaviour among adolescents. This is because mass media has been shown to exert great influence on the behaviour of young people. Adolescents who are exposed to sexual contents on the media are likely to indulge in similar behaviour. Again because media has made sex fashionable and trendy, most of the advertisements have sexual suggestions and associations to them. The media therefore would seem to be promoting in their study. Brown, L, Engle, Pardon, Guo, Kenneary, Jackson (2006) opined that adolescent consistently site the mass media as important sources of sexual information. This finding is in line with the finding of Wolak et al. (2007), who states that in addition to higher likelihoods that an adolescent exposed to sexual content in the media will engage in risky sexual behaviours. The finding also agrees with Collins, et al. (2004), who opines that adolescents who see characters having casual sex without experiencing negative consequences will be more likely to adopt the behaviours portrayed.

The finding also revealed that there is a significant influence of school location on the realtionship between mass madia and risky sexual behaviour among adolescents. This finding has shown that school location has an impact on risky sexual behaviour among adolescents. The result further showed that adolescents in rural areas are more likely to engage in risky sexual behaviour than adolescents in urban areas. The plausible reason for this finding is that adolescents in urban areas are more equipped with knowledge in sex education including safe sex behaviours than their counterpart in the rural areas. This finding is at variance with the finding of Ajuwon, et al. (2006), which showed that students whose schools were located in urban areas were 3 times more likely to have had sexual intercourse than those in the rural schools while those in semi-urban schools were almost 2 times more likely to have had sex than students in rural areas. Furthermore the finding disagrees with a study conducted by Slap, Lot, Thiang, Damiyam, Zinc and Suecop (2003) which showed that risky sexual behaviour is higher in urban than rural areas because adolescents in rural areas are surrounded by various norms and traditions which they must uphold or face the corresponding consequences.

\section{Conclusion and Recommendations}

Media is an important channel for portraying information and channelling communication with the most common platform as newspapers, magazines, radio, television and internet, hence the general public relies on the mass media to provide information regarding political issues, social issues, entertainment and news in pop culture. During the adolescence stage outside influences are particularly capable of affecting teenagers thoughts and behaviours and some of such influences are location and social media, consequently adolescents consistently site the mass media as important sources of sexual information. Jones and Fox (2009) mentioned that $93 \%$ of children in the age group of 12-17 years are found to be searching different sites on internet, $21 \%$ have a mobile phone, $57 \%$ watch videos on computer, $63 \%$ visit social networking sites, $38 \%$ make online purchases and $28 \%$ get health information.

The study has been able to establish differences in risky sexual behaviour among adolescents in rural and urban location. It is obvious that majority of some adolescents in the urban setting have higher level of awareness on sexual activities than their rural counterparts due to their exposure, hence adolescents in rural areas tend to be more involved in risky sexual behaviour. Based on the above findings, the study therefore recommends the following:

1. parents should be mindful of the kind of content students are exposed to in the mass and social media

platforms. They should be properly guided on the dangers of imitating sexual activities viewed on television

2. Students from rural schools should be counselled about the consequences of risky sexual behaviour

\section{REFERENCES}

Adeleye, A.O., Oluwatosin, A.A., Adefisoye, A., Oluwaseyi, I.A. \& Abiola, T. (2014). Risky sexual activities among adolescents: Early initiation into sexual activity, sex with many partners, low and inconsistent use of condom. Journal of Behaviural Health, DOI: 10.5455/jbh.

Aggleton, P., Hurry, J. \& Warwick, I. (2000). Young people and mental health. Somerset, NJ: John Wiley and sons. 
Ajuwon, A.J., Olaleye, A. Famoroju, B. and Ladipo, O. (2006) Sexual behaviour and experience of sexual coercion among secondary school students in three states in North Eastern Nigeria. Bio Med Central (BMC) Public Health; $6: 310$.

Andrew (2003). Awake magazine. August 22,p.19.

Ashby, S., Arcari, C., \& Edmonson, B. (2006). Television viewing and risk of sexual initiation by young adolescents. Archives of Pediatric and Adolescent Medicine,160, 375-380.

Baumeister, L.M., Flores, E. \& Marin, B.U. (1995). Sex information given to Latina adolescents by parents. Health Education Research, 10(2): 233-239.

Brown, J.D., L’Engle, K.L., Pardun, C.J., Guo G., Kenneavy, K. \& Jackson, C. (2006). Sexy media matter: Exposure to sexual content in music, movies, television and magazines predicts black and white adolescents' sexual behaviour. Pediatrics, 117 (4): 1018-10270.

Collins, R.L., Elliott, M.N., Berry, S.H., Kanouse, D.E., Dale, K., Hunter, S.B. \& Miu, A. (2004). Watching sex on television predicts adolescent initiation of sexual behaviour. American Academy of Paediatrics, 114(3): 280289.

De Vincenzi (1994). Human sexuality. 2nd ed. Boston: little Brown \& co.

Ekwueme, M. N. (2012). Environmental determinants of risky sexual behaviour among secondary school adolescents in Obollo-Afor Education Zone of Enugu State. Unpublished M.Ed. Dissertation, University of Nigeria, Nsukka.

Famutimi, E.O. \& Oyetunde, M.O. (2014). Risky sexual behaviour among secondary school adolescents in Ibadan North Local Government Area, Nigeria. Journal of Nursery and Health Science, 3(3).

Folayan, M.O., Adebajo, S., Adeyemi, A., \& Ogungbemi, K.M. (2015). Differences in sexual practices, sexual behaviour and HIV risk profile between adolescents and young persons in rural and urban Nigeria. Journald.Plos.Org., 10(7), e0129106.

Gerbner, G., Gross, L., Morgan, M., \& Signorielli, N. (1986). "Living with television: The dynamics of the cultivation process" in J. Bryant \& D. Zillman (Eds.), Perspectives on media effects (pp. 17-40). Hilldale, NJ: Lawrence Erlbaum Associates.

Jones, S. \& Fox, S. (2009). Generations online in 2009. Washington, DC: Pew Internet and American Life Project. Retrieved from www.pewinternet.org/_/media// Files/Reports/2009/PIP_Generations_2009.pdf retrieved on 25-11-2012

Kimani, J.M. (2014). Relationship between levels of exposure to mass media and students' deviant behaviours in selected secondary schools within Nakuru County Kenya. Unpublished Ph.D. Thesis, Kenyata University, Kenya.

Klein, J.D., Brown, J.D., Dykers, C., Childers, K.W., Oliveri, J. \& Porter, C. (1993). Adolescents' Risky Behaviour and Mass Media Use. Pediatrics, 92 (1).

Ojong, I.N., Achi, M.M. \& Kalun, U.V. (2016). Determinants of Reproductive Health Awareness among Secondary School Students in Northern, Cross River State, Nigeria. International Journal of Science and Research Methodology, 5(2), 136-143.

Oladeji, D. \& Ayangunna, J.A. (2017). Media Influence as Predictors of Adolescent's Sexual Risky Behaviour in Nigeria. MOJ Women's Health. 5 (1): 00112. DOI: 10.15406/mojwh.2017.05.00112

Olumuyiwa, V. \& Oladipupo-Okorie, B.O. (2014). Pre-marital sex among secondary school students: Do mass media and peer group matter? International Journal of Development and Sustainability, 3(7), 1549-1557. 
Oluwatosin, S. A. \& Adediwura, A. A. (2010). Undergraduates' History of Sexual Abuse, Parenting Style and Sexual Risk Behaviour in Southwestern Nigeria. An International Multi-Disciplinary Journal, 4(2), 139-155.

Pearson, A. L. (2013). The Impact of Parenting Styles on the Emotional Regulation of Adolescents. Unpublished M.Sc. Dissertation, St. Catherine University and the University of St. Thomas St. Paul, Minnesota. Retrieved $23^{\text {rd }}$ January, 2019 from https://sophia.stkate.edu/msw_papers/248

Robinson (1999). Institute of Medicine, Department of Health and Human Services.

Santrock, J. W. (2000). Psychology: University of Texas at Dollas (6th Ed).

Slap, G.B., Lot, L., Houang, B., Daniyam, C.A., Zink, T.M. \& Succop, P.A. (2003). Sexual behaviour of adolescents in Nigeria: Cross sectional survey of secdondary school students Pub. Med. Gov. Division of Adolescent Medicine, University of Cincunnati College of Medicine, (ML-4000) 3333 Burnet Avenue.owo USA.

Ugoji, F.N. (2014). Determinants of Risky Sexual Behaviours among Secondary School Students in Delta State Nigeria. International Journal of Adolescents and Youth. Vol. 19 (3). Pp. 408-418. https://doi.org/10.1080/02673843.2012.751040

Wakefield, M.A., Loken, B. \& Hormell, R.C. (2010). Use of mass media campaigns to change health behaviour. Lancet, 376: 1261-1271.

Ward, C. A. (1995). Attitudes Toward Rape: Feminist and Social Psychological Perspectives. London: Sage Publications, 232 pp.

Wolak, J., Funkelhor, D., Kimberly, J.M. \& Ybarra, M.L. (2008). Online "Predators" and their Victims. Myths, Realities and Implications for Prevention and Treatment. American Psychologist, 63(2): 111-128. 